\title{
ANALYSIS OF CENTRAL FOVEAL THICKNESS, FOVEAL SENSITIVITY, MACULAR VOLUME AND CORNEAL THICKNESS AMONG TYPE 2 DIABETES MELLITUS WITH OR WITHOUT ALBUMINURIA
}

\author{
Shruthy Vaishali R', Ashok Balagopal2, Ramesh Rajasekaran³, R. Meena Kumari', Kalai Mohan ${ }^{5}$ \\ 1 Postgraduate Student, Department of Ophthalmology, Mahatma Gandhi Medical College and Research Institute, Puducherry, India. \\ ${ }^{2}$ General Ophthalmologist, Department of Ophthalmology, Mahathma Eye Hospital, Tiruchirappalli, Tamilnadu, India. \\ ${ }^{3}$ Chairman, Mahathma Eye Hospital, Tiruchirappalli, Tamilnadu, India. \\ ${ }^{4}$ Medical Director, Mahathma Eye Hospital, Tiruchirappalli, Tamilnadu, India. \\ ${ }_{5}^{5}$ General Ophthalmologist, Department of Ophthalmology, Mahathma Eye Hospital, Tiruchirappalli, Tamilnadu, India.
}

\section{BACKGROUND}

ABSTRACT

Albuminuria is known to be associated with diabetic retinopathy. Science and technology have proved many histological similarities between glomerulus and capillaries of retina. The present study aimed to investigate the foveal thickness, foveal sensitivity, macular volume and corneal thickness among type 2 Diabetes Mellitus (DM) among newly detected patients and patients who are already on medication. This was correlated in patients with and without albuminuria. This study will bring out the status of retina and cornea among Type 2 DM patients.

\section{MATERIALS AND METHODS}

This is a retrospective analysis of both sexes above 40 years of age affected with Type 2 diabetes mellitus (DM). Patients were examined clinically and evaluated by laboratory means and assessed by conventional and advanced technology and the details were analysed. Cross Sectional design and Cluster Random Sampling was followed. This study work has been approved by Institutional Ethics Committee (IEC). All cases of type 2 DM attending the hospital has been considered for the study. They were known diab etics or newly diagnosed Type $2 \mathrm{DM}$. Healthy age and sex matched people $(\mathrm{N}=50)$ were taken as control for the study. An informed consent was obtained from patients who participated in the study. The observation made out of the study was correlated with laboratory and clinical parameters and there by the probable predicable findings of the Diabetic Retinopathy will be identified. Thus, early markers of diabetic retinal changes will be identified, and knowledge gained will be taken to educate the professional community and students of health sciences. This study is expected to bring out an association between central corneal thickness, central foveal thickness, macular volume and albuminuria.

\section{RESULTS}

There was negligible correlation between micro albuminuria and central foveal thickness, macular volume, foveal sensitivity and central corneal thickness.

\section{CONCLUSION}

Out of the sample size of 122 patients with and without micro albuminuria, various variables like foveal thickness, macular volume, foveal sensitivity and corneal thickness were studied. Statistically significant positive correction was found between central foveal thickness and macular volume. But there is no significant correlation between foveal thickness, macular volume, foveal sensitivity and corneal thickness in Type $2 \mathrm{DM}$ with or without micro albuminuria.

\section{KEY WORDS}

Diabetes, Albuminuria, Foveal Thickness, Foveal Sensitivity, Macular Volume, Corneal Thickness, Type 2 DM.

HOW TO CITE THIS ARTICLE: Vaishali SR, Balagopal A, Rajasekaran R, et al. Analysis of central foveal thickness, foveal sensitivity, macular volume and corneal thickness among type 2 diabetes mellitus with or without albuminuria. J. Evolution Med. Dent. Sci. 2018;7(51):5447-5451, DOI: 10.14260/jemds/2018/1205

\section{BACKGROUND}

The incidence of diabetes is expected to increase by 366 million globally by 2030 . According to WHO, the prevalence rate of nephropathy after 15 years of diabetes ranged between $17.7 \%$ to $56.6 \%$ in men and between $11.9 \%$ to $71 \%$ in women. The concordance of albuminuria and diabetic retinopathy has been well reported in persons with type 1

'Financial or Other Competing Interest': None.

Submission 01-11-2018, Peer Review 05-12-2018,

Acceptance 08-12-2018, Published 17-12-2018.

Corresponding Author:

Dr. Shruthy Vaishali $R$,

Postgraduate Student, Department of Ophthalmology,

Mahatma Gandhi Medical College and Research Institute,

Puducherry, India.

E-mail: vaishusmail@gmail.com

DOI: $10.14260 /$ jemds/2018/1205

diabetes. ${ }^{1}$ However for type 2 diabetes, there is paucity of data regarding association of albuminuria and diabetic retinopathy. The same applies to correlating albuminuria with central foveal thickness, macular volume, foveal sensitivity and corneal thickness. ${ }^{2}$ Central foveal thickness, macular volume, foveal sensitivity and corneal thickness are an emerging concept in the field of ophthalmology. Association between these parameters and diabetes has not been studied much. The relationship between these parameters and albuminuria has not been analysed by very many. Longer diabetes duration and poorer glycemic and blood pressure control are strongly associated with diabetic retinopathy. The magnitude of damage caused by these micro vascular complications of diabetes mellitus, stresses the need for sensitive markers to screen for retinopathy and nephropathy. The sensitive marker for the detection of diabetic nephropathy is to estimate the 
excretion of protein in urine and to detect diabetic retinopathy after dilated fundus examination. ${ }^{3}$

The international diabetes federation guidelines recommended the early detection of diabetic retinopathy by means of diabetic retinopathy screening. All this is being done because India has become a capital country producing large turnover of diabetics. ${ }^{4}$ As a result, the social and economic burden on our country is huge. Lots of risk markers for early detection of diabetic retinopathy were also analysed by various authors. Search for risk markers was carried out because of the magnitude of legal blindness or total blindness caused by diabetic retinopathy.

Hence the present study is undertaken to find out the status of retina and cornea in type $2 \mathrm{DM}$ with and without albuminuria and correlate them with the retina status.

\section{MATERIALS AND METHODS}

This is a retrospective cross-sectional study of both male and female. All the patients belong to type $2 \mathrm{DM}$ either known diabetics or newly diagnosed ones. Inclusion criteria includes those who are aged 40 years and above. Exclusion criteria involve patients with any retinal disorder previously treated for diabetic retinopathy, ocular and media opacity, glaucoma congenital ocular malformations, eye infection. ${ }^{5}$

The variables used in the study were foveal thickness, foveal sensitivity, macular volume and corneal thickness. A total number of 122 type 2 diabetics were analysed for the study. Albuminuria estimation was done using a semi quantitative procedure (Bayer Clinitek 50 urine chemistry analysis) with the first morning urine sample. Status of diabetic retinopathy was clinically graded using early treatment diabetic retinopathy scales. ${ }^{6}$ This was done in the hospital in a masked fashion by two different observers.

Fundus findings were recorded after pupillary dilation using Topcon fundus camera. Seven standard photographs of the fundus were taken and interpreted.

Visual acuity was assessed routinely for all patients using Snellen's visual acuity charts. Using a spectral domain Optical Coherence Tomography (OCT), central foveal thickness and macular volume was assessed. Microperimetry was used to check the foveal sensitivity in all cases. Pachymetry was done to evaluate central corneal thickness in all cases. ${ }^{7}$

Patients with Type 2 DM were identified based on American Diabetic Association criteria. Patients with known DM were those who were previously diagnosed cases of diabetes whether or not they were using any oral antiglycemic drug or insulin or both. The newly diagnosed diabetics were those who had their fasting blood glucose $\geq$ $110 \mathrm{mg} / \mathrm{dl}$ on two separate days. They were enrolled for our study.

If the albumin creatinine ratio (ACR) was between 30 $299 \mathrm{mg} / \mathrm{gm}$. diagnosis of micro albuminuria ${ }^{8}$ was made. Anything less than this was taken as normal values. Those above $300 \mathrm{mg} / \mathrm{gm}$. was diagnosed as macro albuminuria and excluded from the study

Intraocular pressure was measured in both the eyes using Goldmann applanation tonometer ${ }^{9}$ by applying $0.05 \%$ proparacaine eye drops as topical anaesthesia and $2 \%$ fluorescein to stain tear film. Values above $21 \mathrm{~mm}$ of $\mathrm{Hg}$ was considered abnormal and deleted from the study. This instrument was calibrated ones a week. Anterior segment examination was done using slit lamp bio-microscopy. Patients with shallow anterior chamber or any media opacities were identified by the slit lamp and deleted from the study.

Dilated fundus examination was done Fundus of both the eyes were examined using direct ophthalmoscope, indirect ophthalmoscope and also 90D lens. 7 standard colour fundus photographs were taken using Topcon $50 \mathrm{X}$ fundus camera. The diabetic retinopathy grading was done by two independent observers by Modified ETDRS (Early Treatment Diabetic Retinopathy Study) scales. Clinically significant macular oedema was diagnosed based on the ETDRS scale.

\section{OCT}

Spectral domain OCT was utilized to study foveal thickness and macular volume. An average of 6 radial lines passing through the center of the fovea was taken as foveal thickness. Fast macular map protocol was used to study macular volume. Microperimetry was performed. Wherever there was clinically significant macular oedema or diffuse diabetic macular oedema an overlay of the Microperimetry was done using the macular cube protocol so that foveal sensitivity was correlated with the macular pathology.

The diagnosis of CSME or DDME was made purely by slit lamp bio microscopy using 90D lens/78D lens and by direct ophthalmoscope.

\section{Pachymetry}

All patients were subjected to measurement of Central Corneal Thickness of both eyes by a single ophthalmic technician. 10 \& 11 Due to paucity of normative data regarding Spectral domain OCT, the own normative data was developed

\section{RESULTS}

The present study was focused to analyse the association between central corneal thickness, central foveal thickness, macular volume and albuminuria. The variables used in the study were foveal thickness, foveal sensitivity, macular volume and corneal thickness. In the present study, out of 122 type $2 \mathrm{DM}, 40(33 \%)$ of them were found to have micro albuminuria (Table -1). From this study, it was inferred that, every 3 individuals in the population of type $2 \mathrm{DM}$ is likely to have micro albuminuria. 82 (62\%) of them, did not have micro albuminuria. Distribution of type 2 diabetic patients in relation to diabetic retinopathy staging with micro albuminuria was recorded. The results showed that, out of 40 cases with micro albuminuria, 12 of them had diabetic retinopathy with various severities. Out of this 3 had mild NPDR and 2 had Severe NPDR and 6 had PDR (Table 3).

In our study, out of 82 cases without micro albuminuria, 14 $(17 \%)$ of them were found to have diabetic retinopathy of various severity. Out of these, 7 had mild NPDR, 2 had severe NPDR, 1 had very severe NPDR and 4 had PDR with TRD. The results were predicted in table- $2 \& 4$.

The central foveal thickness in 40 cases of type $2 \mathrm{DM}$ with micro albuminuria were studied. Out of this, 12 had diabetic retinopathy out of which these 2 of them had increased central foveal thickness and 2 had reduced central foveal thickness. The two patients with increased central foveal thickness had severe NPDR and 2 patients with decreased central foveal thickness had moderate visual loss.

The central foveal thickness of 82 cases without micro albuminuria showed different types of observation. 14 diabetic type $2 \mathrm{DM}$ patients had diabetic retinopathy, out of 
which 5 had increased central foveal thickness and 3 had decreased central foveal thickness. The reduced central foveal thickness may be due to foveal ischaemia which needs confirmation with Fundus fluorescein angiography.

The macular volume analysis of 40 cases with micro albuminuria were studied. Among the 40 cases, 12 had diabetic retinopathy from which 3 patients had high macular volume and 1 had decreased macular volume. Out of the 82 cases without micro albuminuria 14 had diabetic retinopathy out of which 5 had raised macular volume and 1 had decreased macular volume. The increase in macular volume was found in patient with severe NPDR, very severe NPDR and PDR.

Foveal sensitivity study showed that, out of the 40 patients with micro albuminuria, 12 had diabetic retinopathy, from which 5 of them had decreased foveal sensitivity as proven by Microperimetry. Of the 82 cases without micro albuminuria 14 had diabetic retinopathy of which 5 of them had decreased foveal sensitivity.

Central corneal thickness of the 40 patients with micro albuminuria showed 12 diabetic retinopathy patients, from which 2 had increased central corneal thickness. For those without micro albuminuria, 4 of them had increased corneal thickness (Table 5).

\begin{tabular}{|c|c|c|c|c|}
\hline $\begin{array}{l}\text { Age } \\
\text { Group }\end{array}$ & Male & \begin{tabular}{|l|}
$\%$ of Patients \\
with Micro- \\
Albuminuria
\end{tabular} & Female & $\begin{array}{c}\% \text { of Patients } \\
\text { with Micro- } \\
\text { Albuminuria }\end{array}$ \\
\hline $40-45$ & 4 & 16.66667 & 3 & 18.75 \\
\hline $45-50$ & 3 & 12.5 & 0 & 0 \\
\hline $50-55$ & 6 & 25 & 1 & 6.25 \\
\hline $55-60$ & 5 & 20.83333 & 7 & 43.75 \\
\hline $60-65$ & 4 & 16.66667 & 4 & 25 \\
\hline $65-70$ & 1 & 4.166667 & 1 & 6.25 \\
\hline $70-75$ & 1 & 4.166667 & 0 & 0 \\
\hline & 24 & & 16 & \\
\hline
\end{tabular}

\begin{tabular}{|c|c|c|c|c|}
\hline $\begin{array}{c}\text { Age } \\
\text { Group }\end{array}$ & Male & $\begin{array}{c}\text { \% of Patients } \\
\text { without Micro- } \\
\text { Albuminuria }\end{array}$ & Female & $\begin{array}{c}\text { \% of Patients } \\
\text { without } \\
\text { Micro- } \\
\text { Albuminuria }\end{array}$ \\
\hline $40-45$ & 5 & 12.19512 & 5 & 12.19512 \\
\hline $45-50$ & 3 & 4.878049 & 4 & 9.756098 \\
\hline $50-55$ & 3 & 7.317073 & 7 & 17.07317 \\
\hline $55-60$ & 10 & 24.39024 & 11 & 26.82927 \\
\hline $60-65$ & 7 & 17.07317 & 6 & 14.63415 \\
\hline $65-70$ & 9 & 21.95122 & 3 & 7.317073 \\
\hline $70-75$ & 5 & 12.19512 & 5 & 12.19512 \\
\hline & $\mathbf{4 1}$ & & $\mathbf{4 1}$ & \\
\hline
\end{tabular}

Table 2. Distribution of Cases in relation to Age and Gender without Microalbuminuria

\begin{tabular}{|c|c|c|c|c|c|c|}
\hline \multirow{2}{*}{$\begin{array}{c}\text { Age } \\
\text { Group }\end{array}$} & \multirow{2}{*}{ Male } & \multicolumn{2}{|c|}{ Stage } & \multirow{2}{*}{ Female } & \multicolumn{2}{|c|}{ Stage } \\
\cline { 3 - 6 } & & RE & LE & & RE & LE \\
\hline $40-45$ & 1 & $\begin{array}{c}\text { Stable } \\
\text { PDR }\end{array}$ & $\begin{array}{c}\text { Pnstable } \\
\text { PDR }\end{array}$ & 1 & PDR & PDR \\
\hline $45-50$ & - & - & - & - & -- & - \\
\hline \multirow{2}{*}{$50-55$} & 1 & PDR & PDR & 1 & $\begin{array}{c}\text { Mild } \\
\text { NPDR }\end{array}$ & $\begin{array}{c}\text { Mild } \\
\text { NPDR }\end{array}$ \\
\cline { 3 - 6 } & 2 & PDR & PDR & - & - & - \\
\hline \multirow{2}{*}{$55-60$} & 1 & $\begin{array}{c}\text { Severe } \\
\text { NPDR }\end{array}$ & $\begin{array}{c}\text { Severe } \\
\text { NPDR }\end{array}$ & 1 & PDR & PDR \\
\cline { 3 - 4 } & 2 & PDR & $\begin{array}{c}\text { Unstable } \\
\text { PDR }\end{array}$ & - & - & - \\
\hline
\end{tabular}

\begin{tabular}{|c|c|c|c|c|c|c|}
\hline \multirow{2}{*}{$60-65$} & 1 & $\begin{array}{c}\text { Mild } \\
\text { NPDR }\end{array}$ & $\begin{array}{c}\text { Mild } \\
\text { NPDR }\end{array}$ & - & - & - \\
\cline { 2 - 7 } & 2 & $\begin{array}{c}\text { Severe } \\
\text { NPDR }\end{array}$ & $\begin{array}{c}\text { Severe } \\
\text { NPDR }\end{array}$ & - & - & - \\
\hline $65-70$ & 1 & $\begin{array}{c}\text { Mild } \\
\text { NPDR }\end{array}$ & $\begin{array}{c}\text { Mild } \\
\text { NPDR }\end{array}$ & - & - & - \\
\hline $70-75$ & 1 & $\begin{array}{c}\text { Severe } \\
\text { NPDR }\end{array}$ & $\begin{array}{c}\text { Severe } \\
\text { NPDR }\end{array}$ & - & - & - \\
\hline \multicolumn{7}{|c|}{ Table 3. Distribution of Cases in relation to Diabetic } \\
Retinopathy Staging with Microalbuminuria \\
\hline
\end{tabular}

\begin{tabular}{|c|c|c|c|c|c|c|}
\hline \multirow{2}{*}{$\begin{array}{l}\text { Age } \\
\text { Group }\end{array}$} & \multirow{2}{*}{ Male } & \multicolumn{2}{|c|}{ Stage } & \multirow{2}{*}{ Female } & \multicolumn{2}{|c|}{ Stage } \\
\hline & & RE & LE & & RE & LE \\
\hline \multirow[t]{2}{*}{$40-45$} & 1 & $\begin{array}{l}\text { Stable } \\
\text { NPDR }\end{array}$ & $\begin{array}{c}\text { Unstable } \\
\text { NPDR }\end{array}$ & 1 & $\begin{array}{l}\text { Mild } \\
\text { PDR }\end{array}$ & $\begin{array}{l}\text { Mild } \\
\text { PDR }\end{array}$ \\
\hline & & & & 2 & PDR & PDR \\
\hline $45-50$ & - & - & - & 1 & PDR & PDR \\
\hline \multirow{4}{*}{$50-55$} & 1 & PDR & PDR & & & \\
\hline & 7 & Moderate & Moderate & \multirow{2}{*}{1} & \multirow{2}{*}{ Normal } & \multirow{2}{*}{ Normal } \\
\hline & 2 & NPDR & NPDR & & & \\
\hline & 3 & $\begin{array}{l}\text { Mild } \\
\text { NPDR }\end{array}$ & $\begin{array}{l}\text { Mild } \\
\text { NPDR }\end{array}$ & - & - & - \\
\hline \multirow{4}{*}{$55-60$} & 1 & $\begin{array}{l}\text { Mild } \\
\text { NPDR }\end{array}$ & $\begin{array}{l}\text { Mild } \\
\text { NPDR }\end{array}$ & 1 & $\begin{array}{l}\text { Mild } \\
\text { NPDR }\end{array}$ & $\begin{array}{c}\text { Mild } \\
\text { NPDR }\end{array}$ \\
\hline & 2 & $\begin{array}{c}\text { Severe } \\
\text { NPDR }\end{array}$ & $\begin{array}{l}\text { Mild } \\
\text { NPDR }\end{array}$ & 2 & $\begin{array}{l}\text { PDR } \\
\text { With } \\
\text { CSME }\end{array}$ & $\begin{array}{l}\text { PDR } \\
\text { With } \\
\text { CSME }\end{array}$ \\
\hline & 3 & $\begin{array}{c}\text { Severe } \\
\text { NPDR } \\
\end{array}$ & \begin{tabular}{c|} 
Severe \\
NPDR \\
\end{tabular} & 3 & \begin{tabular}{|c|} 
Mild \\
NPDR \\
\end{tabular} & $\begin{array}{c}\text { Mild } \\
\text { NPDR }\end{array}$ \\
\hline & 4 & PDR & $\begin{array}{c}\text { PDR with } \\
\text { CSME }\end{array}$ & - & - & - \\
\hline \multirow{3}{*}{$60-65$} & 1 & $\begin{array}{l}\text { Very } \\
\text { Severe } \\
\text { NPDR }\end{array}$ & \begin{tabular}{|c|} 
Very \\
Severe \\
NPDR
\end{tabular} & 1 & $\begin{array}{c}\text { Mild } \\
\text { NPDR }\end{array}$ & $\begin{array}{l}\text { Mild } \\
\text { NPDR }\end{array}$ \\
\hline & 2 & $\begin{array}{c}\text { Mild } \\
\text { NPDR }\end{array}$ & $\begin{array}{c}\text { Mild } \\
\text { NPDR }\end{array}$ & - & - & - \\
\hline & 3 & $\begin{array}{c}\text { Severe } \\
\text { NPDR }\end{array}$ & $\begin{array}{c}\text { Severe } \\
\text { NPDR }\end{array}$ & - & - & - \\
\hline \multirow{3}{*}{$65-70$} & 1 & \begin{tabular}{|c|} 
Mild \\
NPDR \\
\end{tabular} & \begin{tabular}{|c|} 
Mild \\
NPDR \\
\end{tabular} & - & - & - \\
\hline & 2 & PDR with & PDR with & - & - & - \\
\hline & 3 & Normal & PDR & - & -- & - \\
\hline \multirow[b]{2}{*}{$70-75$} & 1 & $\begin{array}{c}\text { Severe } \\
\text { NPDR }\end{array}$ & $\begin{array}{c}\text { Severe } \\
\text { NPDR }\end{array}$ & 1 & $\begin{array}{c}\text { Mild } \\
\text { NPDR }\end{array}$ & $\begin{array}{c}\text { Mild } \\
\text { NPDR }\end{array}$ \\
\hline & 2 & $\begin{array}{c}\text { Severe } \\
\text { NPDR }\end{array}$ & $\begin{array}{c}\text { Moderate } \\
\text { NPDR }\end{array}$ & 2 & $\begin{array}{l}\text { PDR } \\
\text { with } \\
\text { TRD }\end{array}$ & $\begin{array}{l}\text { PDR } \\
\text { with } \\
\text { TRD }\end{array}$ \\
\hline
\end{tabular}

Table 4. Distribution of Cases in relation to Diabetic Retinopathy Staging without Microalbuminuria

\begin{tabular}{|l|c|c|c|c|c|c|}
\hline \multirow{2}{*}{$\begin{array}{c}\text { Age } \\
\text { Group }\end{array}$} & \multirow{2}{*}{ Male } & \multicolumn{2}{|c|}{ Pachymetry } & \multirow{2}{*}{ Female } & Pachymetry \\
\cline { 3 - 7 } & & RE & LE & & RE & LE \\
\hline $40-45$ & - & - & - & 1 & 615 & 615 \\
\hline $45-50$ & - & - & - & - & - & - \\
\hline $50-55$ & - & - & - & 1 & 616 & 616 \\
\hline $55-60$ & - & - & - & - & - & - \\
\hline $60-65$ & - & - & - & 1 & 615 & 615 \\
\hline $65-70$ & - & - & - & - & - & - \\
\hline $70-75$ & - & - & - & 1 & 615 & 595 \\
\hline \multicolumn{7}{|c|}{} \\
\hline
\end{tabular}

In our study micro albuminuria was found to exist in 33\% of our study group. The increased levels of urine albumin secretion may represent a more general vascular damage 
than renal micro vascular injury alone. Detection of micro albuminuria ${ }^{12}$ identifies the patients who need a vigorous cardiovascular risk management, management of dyslipidaemia, intensive blood pressure control and strict attention to glycemic control which in turn delays the onset of diabetic retinopathy or if diabetic retinopathy is already present is delays the progression ${ }^{13}$ of diabetic retinopathy.

In our study, a significant correlation was found between the prevalence of micro albuminuria and the duration of diabetes that was consistent with that finding of past studies. Further data analysis reveals, severe form of PDR presentation of diabetic retinopathy incidence was more in the micro albuminuria group compare to those without micro albuminuria. Though the without albuminuria had diabetic retinopathy of various severity the incidence of mild NPDR was more than the others.

Regarding foveal thickness, 2 patients with micro albuminuria and three patients without micro albuminuria were found have decreased values. Of these 5 patients, 3 of them had severe visual loss and 2 had moderate visual loss. 2 patients with moderate visual loss but no diabetic retinopathy requires for the investigation with $\mathrm{FFA}$, to identify whether there is any foveal ischaemia. A fascinating finding is both these patients had micro albuminuria ${ }^{14}$ with moderate visual loss and no diabetic retinopathy.

Macular volume was found out to analyse whether abnormal macular volume could be a precursor for mild NPDR. Those found to have increased macular volume also had clinically significant macular oedema or diffuse diabetic macular oedema. Patients with decreased macular oedema had mild NPDR. Further evaluation with the form of FFA is required to prove whether decreased macular volume was due to macular ischaemia which leads to atrophy of the neurosensory retina. These patients had moderate visual loss.

Foveal sensitivity assessment by using Microperimetry is a newly emerging tool. Those patients with diabetic retinopathy and decreased foveal sensitivity, all of them had macular event like CSME or DDME. They also had PDR and severe NPDR. 3 patients with diabetic retinopathy were found to have decreased foveal sensitivity. Another interesting correlation is that all three of these patients did not have diabetic retinopathy but had micro albuminuria. 15

A Striking feature regarding central corneal thickness is that all patients with increased central corneal thickness had diabetic retinopathy. But all patients without diabetic retinopathy did not have any increased corneal thickness. ${ }^{16}$ Shah et al. (2002) ${ }^{17}$ rejected a statistical correlation between corneal thickness and glycaemia, insulin doses and glycosylated haemoglobin. Leske $(2002)^{18}$ have found a correlation between the duration of diabetes and changes in the cornea, suggesting that such changes, especially at the endothelium level, should be assessed and confirmed before performing intraocular or corneal surgery in chronic diabetics, a hypothesis that justifies the relative contraindication to corneal refractive surgery in diabetes.

In our millennium, diabetic patients exhibit a greater significant average central corneal thickness than nondiabetics. ${ }^{19}$ It is necessary to complement these findings with a parallel study of the corneal endothelium in these patients in order to assess whether there is a correlation between corneal thickness ${ }^{20}$ and conditions of the endothelium in diabetic patients.

\section{CONCLUSION}

Out of the sample size of 122 patients with and without micro albuminuria various variables like foveal thickness, macular volume, foveal sensitivity and corneal thickness were studied. Statistically significant positive correlation was found between central foveal thickness and macular volume. But there is no significant correlation between foveal thickness, macular volume, foveal sensitivity and corneal thickness in Type 2 DM with or without micro albuminuria.

But an observation is that for the patient with decreased foveal sensitivity with decreased macular volume, few of them did not have diabetic retinopathy, but were suffering from some form of visual loss which could be an indicator of foveal ischaemia. Another observation is that the patients with increased central corneal thickness, all of them had diabetic retinopathy. These observations need confirmation with further studies with the large sample size. It was suggested that the application of spectral domain OCT in cases of diabetes is very useful and widely catching up because of its high specificity and high sensitivity, accuracy and reproducibility. It is able to give us foveal thickness, macular volume and foveal sensitivity. But it is an expensive procedure and is not readily available in all districts. Interpreting the OCT also needs high level of expertise, that too from retina specialist and not by a general ophthalmologist whereas measurement of central corneal thickness by pachymetry is less expensive, non-invasive and doesn't require expertise. An elaborate study on the correlation between central corneal thickness and diabetes mellitus needs to be evaluated in the future. This could be a marker or precursor for prediction of diabetic retinopathy before its onset. Foveal sensitivity assessment also looks like a promising tool for suspecting foveal ischaemia.

\section{REFERENCES}

[1] Canadian Diabetes Association Clinical Practice Guidelines Expert Committee. Canadian Diabetes Association 2003 Guidelines for the Prevention and Management of Diabetes in Canada. Can J Diabetes 2003;27(Suppl 2):S66-S71.

[2] Ehlers N, Bramsen T, Sperling S. Applanation tonometry and central corneal thickness. Acta Ophthalmol (Copenh) 1975;53(1):34-43.

[3] Goday A. Epidemiology of diabetes and its noncoronary complications. Rev Esp Cardiol 2002;55(6):657-70.

[4] Kothari V, Stevens RJ, Adler AI, et al. UKPDS 60: risk of stroke in type 2 diabetes estimated by the UK Prospective Diabetes Study risk engine. Stroke 2002;33(7):1776-81.

[5] Stodtmeister R. Applanation tonometry and correction according to corneal thickness. Acta Ophthalmol Scand 1998;76(3):319-24.

[6] Williams R, Airey M, Baxter H, et al. Epidemiology of diabetic retinopathy and macular oedema: a systematic review. Eye (Lond) 2004;18(10):963-83.

[7] Lewis RA. Refractive surgery and the glaucoma patient: customized corneas under pressure. Ophthalmol 2000;107(9):1621-2. 
[8] Wirta O, Pasternack A, Mustonen J, et al. Retinopathy is independently related to microalbuminuria in type 2 diabetes mellitus. Clin Nephrol 1999;51(6):329-34.

[9] Goldmann H, Schmidt T. Uber applanations tonometries. Ophthalmologica 1957;134(4):221-42.

[10] Kniestedt C, Lin S, Choe J, et al. Clinical comparison of contour and applanation tonometry and their relationship to pachymetry. Arch Ophthalmol 2005;123(11):1532-7.

[11] Whitacre MM, Stein R. Sources of error with use of Goldmanntype tonometers. Surv Ophthalmol 1993;38(1):1-30.

[12] Sobngwi E, Mbanya JC, Moukouri EN, et al. Microalbuminuria and retinopathy in a diabetic population of Cameroon. Diabetes Res Clin Pract 1999;44(3):191-6.

[13] Leske MC, Heijil A, Hussein M, et al. Factors for glaucoma progression and the effect of treatment: the early manifest glaucoma trial. Arch Ophthalmol 2003;121(1):48-56.

[14] Weijers RN, Van Merode GG. Retinopathy and microalbuminuria in type 2 diabetes: determinants and time-dependency of the association. Eur J Intern Med 2001;12(1):28-34.
[15] Voutilainen-Kaunisto RM, Terasvirta ME, Uusitupa MI, et al. Occurrence and predictors of retinopathy and visual acuity in type 2 diabetic patients and control subjects. 10-year follow-up from the diagnosis. J Diabetes Complications 2001;15(1):2433.

[16] Doughty MJ, Zaman ML. Human corneal thickness and its impact on intraocular pressure measures: a review and meta-analysis approach. Surv Ophthalmol 2000;44(5):367-408.

[17] Shah S, Chatterjee A, Mathai M, et al. Relationship between corneal thickness and measured intraocular pressure in a general ophthalmology clinic. Ophthalmology 1999;106(11):2154-60.

[18] Leske MC. The epidemiology of open-angle glaucoma: a review. Am J Epidemiol 1983;118(2):166-91.

[19] Whitacre MM, Stein RA, Hassanein K. The effect of corneal thickness on applanation tonometry. Am J Ophthalmol 1993;115(5):592-6.

[20] Wickham L, Edmunds B, Murdoch IE. Central corneal thickness: will one measurement suffice? Ophthalmology 2005;112(2):225-8. 